\title{
A Maintenance Optimzation Policy for an Electric Power Distribution System: Case of the HV/MV Substations
}

\author{
Morad Mahmoudi ${ }^{1,2}$, Abdellah El Barkany², Ahmed El Khalfi² \\ ${ }^{1}$ National Office of Electricity and Water Supply (ONEE), Casablanca, Morocco \\ ${ }^{2}$ Department of Mechanical Engineering, Faculty of Science and Technology, Sidi Mohamed Ben Abdellah \\ University, Fez, Morocco \\ Email: mahmoudimorad@yahoo.fr, a elbarkany2002@yahoo.fr, aelkhalfi@gmail.com
}

Received 8 December 2013; revised 8 January 2014; accepted 16 January 2014

Copyright @ 2014 by authors and Scientific Research Publishing Inc.

This work is licensed under the Creative Commons Attribution International License (CC BY). http://creativecommons.org/licenses/by/4.0/

(c) (i) Open Access

\section{Abstract}

Today, in the modern era, and under the pressure of rapid development around the kingdom regions, electric utilities are confronted with a myriad of challenges that include aging infrastructure, enhanced expectation of reliability, reduced cost, and coping effectively with uncertainties and changing regulation requirements. Indeed, for distribution systems, HV/MV substations represent a complex and critical physical asset that requires a careful evaluation of their maintenance practices aiming at more cost-effective tasks. The first concern of the electric power distribution company in Morocco is the optimization of the distribution network maintenance scheduling, to minimize system operating costs and ensure that the system is running most economically. There is significant pressure on power providers for greater system reliability and improvement of customer satisfaction, while similar emphasis is placed on cost reduction. These cost reductions focus on reducing operating and maintenance expenses, and minimizing investments in new plants and equipment. However, the present of the electricity distribution, influenced by a number of technical restrictions and strict regulatory requirements to meet, leads distribution utilities to search new ways of optimizing the maintenance management, make an effort to maximize profit by reducing their electricity supply and operation costs while maintaining their reliability, developing more effective activities, with lower costs. Furthermore, maximal HV/MV substation asset value and minimal maintenance cost are typical economic objectives of the electric utilities. The optimization of maintenance is one possible technique to reduce maintenance costs while improving reliability and utilities need to implement new strategies for more effective maintenance techniques and Asset Management (AM) methods programs to manage inspections and maintenance activities in order to control HV/MV substation equipment conditions. However, development of strategies to make sound decisions in order to effectively improve equipment and system reliability while meeting constraints such as a maintenance budget is a challenge. Finally, this 
paper describes the application of a new approach based Reliability Centered Maintenance (RCM) methodology to optimize maintenance resources and to the development of maintenance plan for HV/MV distribution substations. For this purpose, a case study was performed on the equipment of power distribution systems for the benefit of a holding company (ONEE Electricity Distribution) in Morocco. The present study was conducted in Oujda Exploitation Maintenance Service (OEXMS), in charge of operation and maintenance of distribution networks.

\section{Keywords}

HV/MV Distribution Substations; Maintenance Strategy; RCM; Optimization; Asset Management

\section{Introduction}

\subsection{Background Information}

Nowadays, electricity distribution industry (EDI) is influenced by a number of facts that affect the development of the business: increasing demand of networks, lower redundancy of systems, operating restrictions that limit maintenance outages, incomes tied to the availability of the installations and so on, together with regulatory frameworks that demand strict technical requirements, imposing severe penalties for its non-accomplishment. In this framework, distribution of electricity, public service activity par excellence, has undergone significant organizational changes in our country with the reorganization of the segment concessions granted by the state, guarantor of public service. The stated situation forces distribution utilities to search new ways of optimizing the maintenance management of their physical assets, aiming at developing their activities more effectively so as to fulfil the requirements imposed in a cost-effective way [1] [2]. Indeed, the maintenance of the High Voltage/ Medium Voltage (HV/MV) distribution substations assets is a challenge both financially and for employees. Due to such a context, HV/MV distribution substations systems (DSS) represent for distribution utilities a critical physical asset for their strategic role to ensure the operation of the distribution systems and the costs involved, not only in their purchase but also in their operation and maintenance (O\&M) along their lifespan [3]. However, the improvement and modernization of public services are a key priority of the authorities and that in response to the expectations and concerns of citizens. The electrical energy network operators, whether private or public, have an obligation to assure constantly the electrical power supply to users who request it. For that purpose, the networks must be able to evolve according to the needs and of the technical requirements. At the origin, the networks have been designed to meet the security requirements in the supply of energy. The concern of the operators went then towards the search for a compromise between the investments and the control of the technical constraints [4] [5].

\subsection{Scope and Aim of the Paper}

The fundamental objective of any electric utility is to plan, operate, maintain and implement expansion of facilities so that customers receive reliable electric services at the lowest possible cost. The purpose of this work is to thus seek and establish unique consideration that needs to be applied when formulating an integrated maintenance strategy to best suit HV/MV DSS. Indeed, the aim of this research study is to develop an appropriate method that will aid strategies for asset management and RCM methodology [6] in electric power distribution substations systems. The feasibility study examined five areas of concern to ONEE/Electricity Distribution (ONEEED) and the ways in which developed methodology could aid ONEEED in these areas. The areas are as follows:

a) To support the ONEEED mission which is to supply reliable power at the least cost and, to provide research leadership to the utility industry.

b) To manage ONEEED resources wisely and to provide a more reliable power supply, better customer service, and fewer emergencies and problems.

c) To reduce costs (There is therefore the need for minimizing the total cost by optimizing the inspection frequency), and to answer questions related to improving maintenance. 


\subsection{Distribution Substations in the Moroccan Electric Distribution Network}

ONEEED, a state owned electricity utility was formed in 1963, with a core business of generating and supplying electricity to the kingdom of Morocco. As a major public enterprise, it has a dominant position in a vital sector of the economy. ONEEED owns and operates the 50\% of Moroccan electric distribution network. The distribution network includes around $195 \mathrm{HV} / \mathrm{MV}$ substations acting as connection points between the high and the middle voltage networks performing the performance of these substations can be an enormous challenge. These substations consist of two transformers ensuring the HV/MV transformation, electro-technical devices (such as circuit breakers, disconnecting and shunts) and a set of electronic hardware (telecommunication, Instrumentation and Control (I\&C)). Substation equipments are important components in power system. Therefore, HV equipment must be maintained its satisfactory operating condition by applying an effective maintenance strategy. Maintenance, availability and reliability are closely related so that a level of maintenance should be specified to ensure an acceptable level of substation reliability. If the maintenance cannot detect and fix the problem in time, the catastrophic failure will occur, which leads to tremendous damage and outage cost to electric utility [7]. As shown in Figure 1, the main components in a distribution substation are [8] [9]:

a) HV Disconnect Switch (SW): security device used to isolate parts of the substation. Load break disconnect switch can open and close with normal load current, no-load break cannot.

b) $\mathrm{HV}$ and MV Bus Bar (BB): rigid conductor used to interconnect primary equipment. Insulator (IS) out of glass or ceramics (See Figure 1).

c) HV and MV Circuit Breakers (CB): Switch that can interrupt fault currents.

d) Auxiliary Transformers: devices used to step down high voltages or currents to levels usable by meters and relays.

e) Power Transformer (PTR): device ensuring the HV/MV transformation.

f) MV Switchgear (SW) and Sectionalized: refers to switches, breakers and MV bus bar located downstream of power transformers.

g) Protection Relays: devices receiving information about the system (voltages, currents, tension, etc.) and sending signals for circuit breakers to open and close when appropriate.

h) Distribution lines or feeders (DL), fuse (F) and arrester (ARS).

i) Substation Automation (SA): SA refers to Supervisory Control and Data Acquisition (SCADA) equipment [3]. It ensures the monitoring of transformers and feeders and the command of (CB).

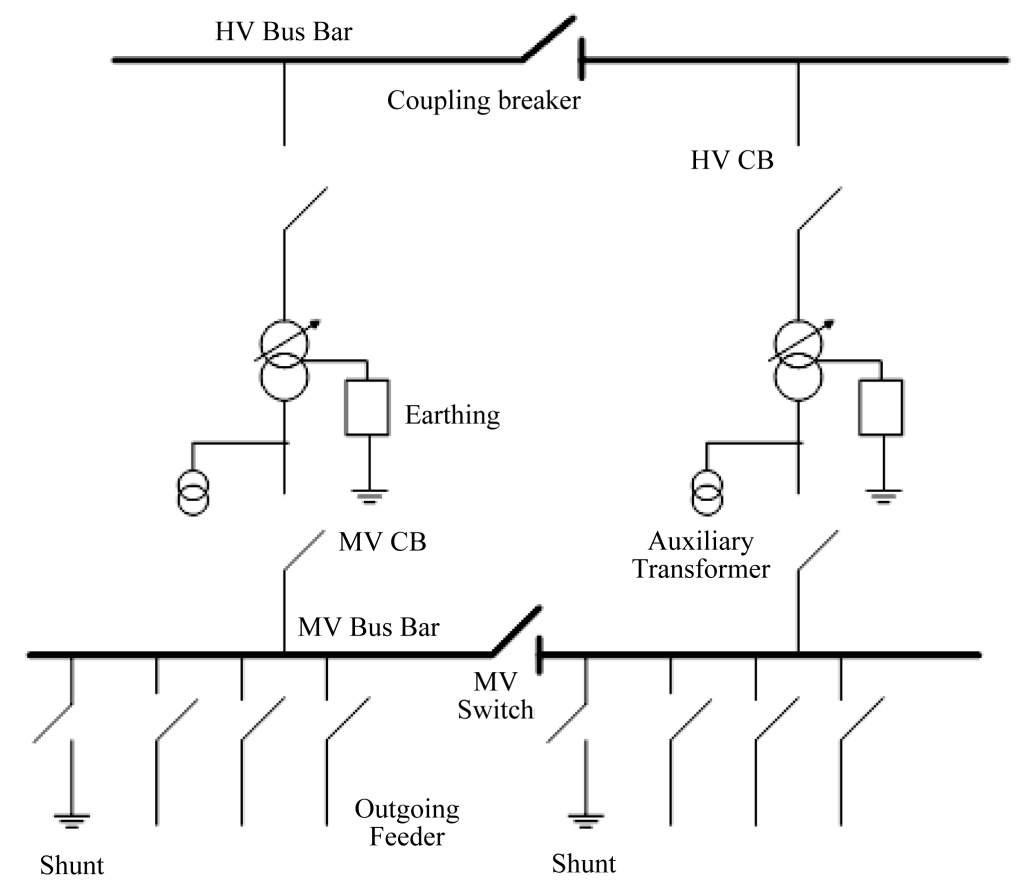

Figure 1. Schematic diagram of a HV/MV DSS. 
Furthermore, ONEEED has adopted a Distribution Management System (DMS), a technical operating system that is helping the efficiency of electrical power delivery to the customers and network management.

This system is the combination of SCADA system and Power Application Software tools (is a key tool for monitoring and operating HV/MV DSS), i.e. state estimator, load flows, short circuit analysis, etc. This operating system integrates the power system data required by the system operators and those of network planners by providing reliable information on the current power system state in real time.

\section{Presentation of HV/MV Substation System Reliability and Maintenance Strategies}

\subsection{The Raliability of a Substation System}

The reliability of a HV/MV DSS refers to the ability of the electric system to provide consumers with continuous electrical service of satisfactory power quality [9]. The electric utility industry maintains a high level of system reliability because when the electric supply to consumers is disrupted, even for a short period of time, the results can range from minor inconvenience to major economic loss to endangerment of human life. Reliability provided to each consumer varies from location to location on the system. Today there is a tendency among electric utilities to defer expenditures for expansion and improvement as long as possible. This tendency results in equipment experiencing more severe operating conditions. Normally, when equipment experiences more severe operating conditions and becomes older, closer attention is given to maintenance. This attention may be in the form of either working harder or working smarter [10]. Maintenance activities may be classified as either corrective or preventive maintenance (PM). Generally, corrective maintenance (CM) is concerned with observed problems while preventive maintenance anticipates problems and initiates action before problems are observed. Reliability techniques may be applied to either corrective or preventive maintenance. It is not possible to manage today power system operation with yesterday methods and remain in business tomorrow. Most chief executive of Companies that are doing well decide to focus on reliability because maintenance is the largest controllable cost in an organization and, without sound asset reliability, losses multiply in many areas [11].

1) Substation System performance indices: Quantitative reliability evaluation of a distribution system can be divided into two basic segments; measuring of the past performance and predicting the future performance. The basic problem with trying to measure reliability is how to relate the two quantities, frequency and duration [11]. One way of solving this is to use any of the methods for solving system performance indices classified below.

a) SAIFI, or System Average Interruption Frequency Index, demonstrates the average number of times per year that the electricity supply to a customer is interrupted, as it is expressed by "Equation (1)".

$$
\text { SAIFI }=\frac{\text { Total Number of Customer Interruptions }}{\text { Total Number of Customers Served }}
$$

b) SAIDI, or System Average Interruption Duration Index, gives the average amount of time per year that the electricity supply to a customer is interrupted, as it is expressed by "Equation (1)".

$$
\text { SAIDI }=\frac{\text { Total Number of Customer Interruptions }}{\text { Total Number of Customers Served }}
$$

c) ENS or Energy Not Supplied denotes the total amount of energy that would have been supplied to the interrupted customers if there were no interruption (KWh/yr), as it is expressed by "Equation (3)".

$$
\text { ENS }=\frac{\text { Total energy Not Supplied }}{\text { Total Number of Customers Served }}
$$

\subsection{Maintenance Strategies and Its Relation to Substation Performance}

The performance of HV/MV DSS is related to performance of its components. Equipment type, age, condition and exposure of events effect on equipment performance and have to be taken into account in maintenance management. The objective is to optimize maintenance costs and efforts in order to ensure competitive electricity price and quality of service. Distribution system operator has power quality and safety requirements that need to be fulfilled. Indeed, interruption cost due to loss of supply to customers is of crucial importance for network owners. This cost depends on failures of the components in the HV/MV DSS. However, the contribution of 
individual components to system failures depends on the reliability characteristics of each component and on its location in the substation structure. Furthermore, maintenance is one of the tools that can be used for ensuring system reliability, other are for example increasing system capacity, reinforcing redundancy and using more reliable components. Usually utilities don't have many possibilities for these actions and have to concentrate on improving status of existing equipment. Indeed, the maintenance schedule must be planned so as to minimize outage costs, taking into consideration various factors such as system security/reliability, system availability, and manpower utilization [12]. For example, the consequences of the failure of a transformer are of a number of different types. There are, of course, economic consequences, including: The replacement of the failed transformer and the making good of the installation, the loss of supply for a substation. Another consequence of failure is risks to the security of installations and the safety of personnel. In the examples considered there is no risk to the security of installations in the case of generator transformers at nuclear power stations, neither is there any risk in the case of the sub-station transformers considered. However, the extreme failure mode for transformers is explosion and this is evidently a risk which must be taken into account in all its aspects, especially in consideration of the safety of personnel or members of the public who may be in the immediate vicinity. However, the maintenance scheduling of HV/MV DSS is a technical and economic optimization problem in which the long-term total cost must be minimized taking into account the technical, environmental, safety related and other constraints. The two metrics that most customers notice about power are its quality and its cost.

Indeed, the maintenance methods used in HV/MV DSS can be divided into two categories: preventive and corrective maintenance. PM is carried out in selected intervals to ensure that equipment works. Intervals could be decided according to time or condition. Objective is to prevent equipment failures. CM is carried out after equipment failure and only in locations where equipment failure doesn't cause significant problems [5] [13]. Consequently, it is crucial to evaluate the importance of each component's effect on the total interruption cost. Furthermore, the knowledge of substation individual components' importance can be used to improve asset management routines for example for maintenance optimization. A well-known method for deducing efficient maintenance plans is the RCM, where PM actions are related to the system reliability. The methods that are used in preventive maintenance can be divided into three categories: time-based maintenance, condition-based maintenance and RCM. These are shortly presented here [10]. See Figure 2.

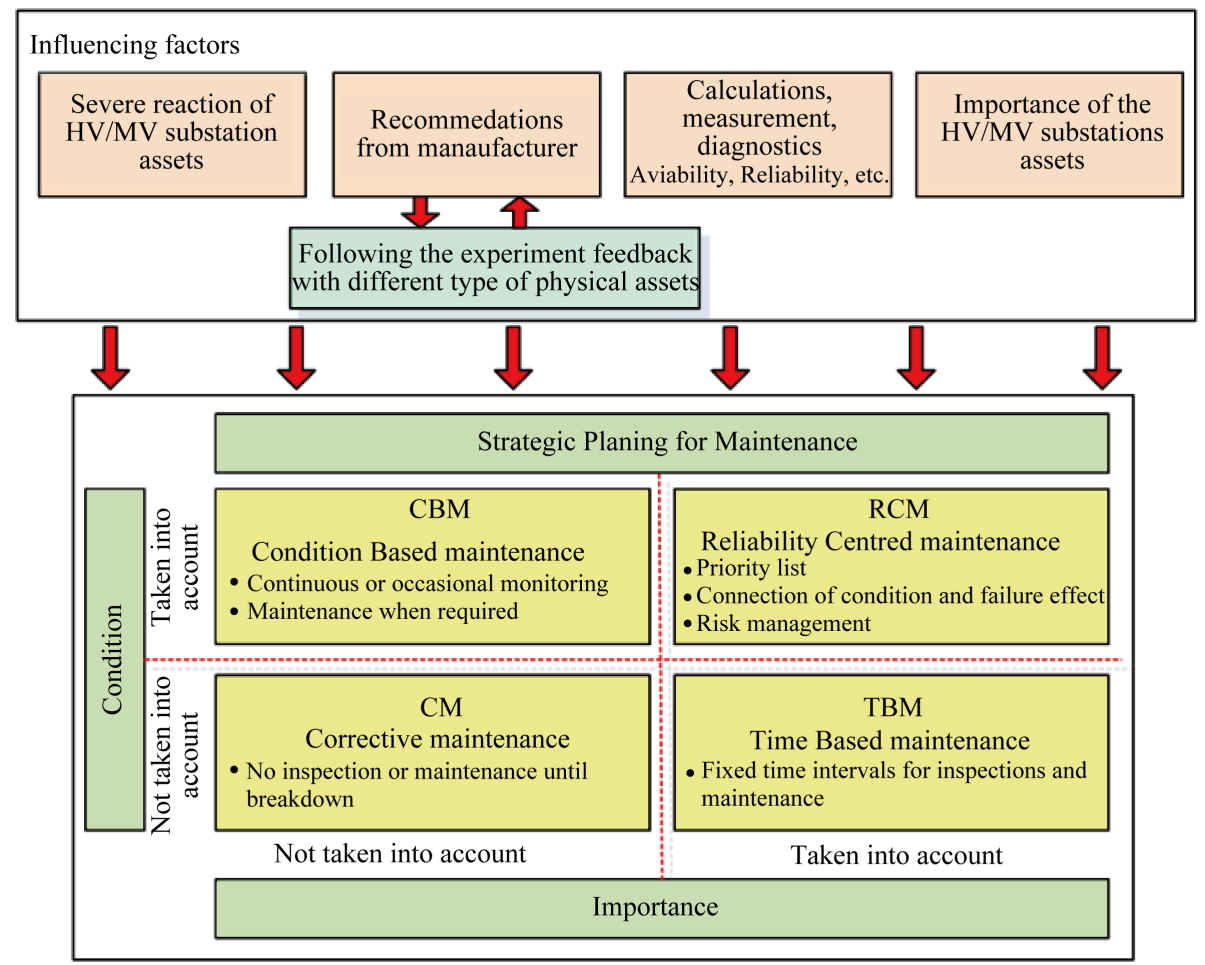

Figure 2. Evolution process of maintenance strategies. 
1) Time-based maintenance (TBM): a TBM strategy featuring predefined intervals rooted in empirical feedback, where components are replaced after a specified period of use, has been practiced as the usual maintenance strategy in electrical power systems for many years. This approach generally produces satisfactory results. It will not however, be the most cost effective option in all cases, since the equipment will not usually remain in operation up to the end of the lifetime, which is possible [10].

2) Condition-based maintenance (CBM): CBM is driven by the technical condition of the equipment. Under this approach, all major parameters are considered in order to determine the technical condition with maximized accuracy. For this reason, detailed information via diagnostic methods or monitoring systems should be available [10] [14], e.g. Under CBM, appropriate maintenance activities for HV/MV DSS are implemented on these assets based on periodic inspection of equipment conditions.

3) RCM and it has to be noticed that this RCM-method is different considering other RCM applications, which consider equipment only. RCM can be described as a systematic approach for identifying and efficient PM tasks for objects in accordance with specific set of procedures. RCM combines several well Known risk analysis techniques and tools, such as failure modes and effects criticality analysis (FMECA), in a systematic approach to managing risk [6] [15]. Figure 2 demonstrates the main conclusion of the different maintenance strategies mentioned above depending on the two criteria: importance of the equipment considering the network and the condition. The presented evolutions of maintenance strategies including the influencing factors give a hint to the expense for applying a certain strategy. A RCM strategy, which combines the two aspects of condition and importance, requires the following procedure:

The condition of the equipment has to be determined: There are several basic possibilities on how to acquire information on the actual condition of network components. The best method from the technical point of view is the on line monitoring of condition related indices of the components [8], e.g. oil temperatures or parameters describing the oil quality of transformers, or the SF6 (Sulfur Hexafluoride) pressure in a gas insulated (CB). The condition of the total HV/MV DSS has to be derived combining the condition of the single items of the asset, for example bays, (CB) and transformers. The condition, e.g. of a (CB), can be evaluated based on different criteria for example: Age, type of (CB), number of short-circuit interruptions, number of switching operations, experience with this, measurement results.

However, the prioritization of network components according to component importance and component condition is a key module of this approach, and requires first the definition of suitable assessment schemes for both component importance and component condition. The importance of the equipment for the substation as a whole must be determined, e.g. the influence of equipment failure on the reliability of supply.

a) Both information inputs must be combined and evaluated in order to specify the optimum sequence of maintenance work for the individual devices (equipment, substation).

4) RCM framework: The RCM analysis may be carried out as a sequence of activities or steps. In IEC standards for RCM analysis [15] [16] following basic steps in an RCM analysis are listed, some of which are overlapping in time [17].

a) Step 1: Study preparation.

b) Step 2: System selection and definition.

c) Step 3: Functional failure analysis (FFA): A specific system was selected in Step 2. The objectives of this step are as follows.

d) Step 4: Critical item selection.

e) Step 5: Data collection and analysis.

f) Step 6: Program FMECA: FMECA is a useful tool when performing an RCM analysis. FMECA is a way to evaluate potential failure modes and their effects and causes in a systematic and structured manner. Failure modes means the ways in which something could fail. Effects analysis refers to studying the consequences of those failures. The purpose of the FMECA is to take actions to eliminate or reduce failures, starting with the highest-priority ones. By itself, an FMECA is not a problem solver; it should be used in combination with other problem solving tools. The analysis can be done either in a qualitatively or quantitatively way. Basic steps in performing a FMECA could be, [18] [19]:

- Define the system to be analyzed. Complete system definition includes defining of system boundaries, identification of internal and interface functions, expected performance, and failure definitions.

- Identify failure modes associated with system failures. For each function, identify all the ways failure could happen. These are potential failure modes. 
- Identify potential effects of failure modes. For each failure mode, identify all the consequences on the system.

- Determine and rank how serious each effect is. The most critical pieces of equipment, which affected the overall function of the system need to, identified and determined.

- For each failure mode, determine all the potential root causes, and for each cause, identify available detection methods.

- Identify recommended actions for each cause that can reduce the severity of each failure.

- Evaluation criteria for different parameters of the FMECA. For the evaluation of failure modes, using the usual parameters of the FMECA, the frequency $\mathrm{O}$, which characterizes occurrence failure modes, the severity $\mathrm{S}$ characterizes the duration of the outage caused by the failure mode detectability and $\mathrm{D}$, which characterizes the probability of detecting the failure before it starts to take corrective or preventive actions. From the three previous parameters, we define C, "Equation (4)" criticality, which is calculated by the product of three factors $\mathrm{O}, \mathrm{S}$ and D. It allows analyzing the risk and setting the threshold of acceptability for each failure mode. Quantification and the choice of values for each parameter were obtained from the history of the index of continuity of service (IC) and the number of interruptions over a period of 7 years from the OEXMS data center. The rating scale is $1-10$ for the three parameters $O, S$ and $D$.

$$
C=O \times S \times D
$$

g) Step 7: Selection of maintenance actions

h) Step 8: Determination of maintenance intervals

i) Step 9: PM comparison analysis

j) Step 10: Treatment of non critical items

k) Step 11: Implementation

l) Step 12: In service data collection and updating

\subsection{Maintenance Optimization for Substations}

Maintenance optimization is here defined as a method aimed at finding the optimal balance between preventive and corrective maintenance with respect to an objective. From a reliability viewpoint the reason for maintenance is quite clear, that is to increase the reliability by means of improving apparatus. Another aspect of maintenance is to reduce risk, usually by inspection, for example; if no cracks are found we can assume that the inspected item will last for some time, in the case of a crack, maintenance actions will be taken. The risk reducing approach can be said to be a subgroup of the main objective (increase reliability), since it is aimed at identifying substandard and/or hazardous equipment. Nevertheless, there are other objectives of maintenance such as appearance and worth of the maintained equipment. Appearance and worth does not necessarily correlate with reliability. Another aspect of maintenance is to make use of existing labor. However, this thesis mainly deals with the reliability objectives, while not diminishing the other aspects of maintenance.

\subsection{Maintenance by the Asset Management}

ONEEED is mobilizing all its resources to speed up and improvement the network quality and drive the same time the two inseparable projects, namely modernization of the network and preventive maintenance of the existing HV/MV assets [20]. To do this, she made the decision to implement and accelerate the redeployment of a solution that is optimal management of its material resources first and then its human and financial resources. It is important to note that maintenance beyond restoring the function of defective equipment is also a vital link in the chain of asset management. Indeed, AM and maintenance of HV/MV DSS thus form a key proportion of modern utility planning and operations. Maintenance is comprised of the various activities performed by utility personal to improve the condition of equipment and enhance their performance. Different strategies have been used by utilities in maintaining and managing the assets. Needless to say, deregulation is also influencing utility perspective to maintenance [21]. In managing physical assets, utilities are being asked to use less of the resources available and to do more (improve system performance). This presents a challenge to the asset manager who is often constrained in the amount of resources available while having a number of maintenance tasks at hand. In order to articulate the argument for various investment proposals and choose the better alternatives, asset managers need tools that can quantify the benefit obtained from maintenance activities and methods to 
optimize the resource allocation to various maintenance programs. The high number of components in distribution networks gives advantages to statistical asset management approaches [12].

AM in electrical grid companies play a key role in the detection and evaluation of decisions leading to longterm economical success and best possible earnings [22]. For asset management to live up to these expectations, it has to meet a number of challenges. The four key challenges are: alignment of strategy and operations with stakeholder values and objectives; balancing of reliability, safety, and financial considerations; benefiting from performance-based rates; and living with the output based penalty regime [23]. For this reason fundamental AM tasks cover aspects from technical issues like network maintenance scheduling or the definition of operational fundamentals to more economical themes like planning of investments and budgeting, and end up in strategic planning issues. The follow diagram can be used to visualize the relationship between the elements of the system. Starting on the left side, Figure 3 shows that the HV/MV DSS assets condition degrades over time due to fundamental ageing processes. This has an impact on network performance which leads to investments if internal performance targets are not met any more. Investments depend on availability of money which directly results from the demands customers are willing to pay for. For example, in a first step the technical condition of the $\mathrm{CB}$ is required which can be evaluated on the basis of different criteria (items of interest), some of which are: age, experience with all type of $\mathrm{CB}$, maximum short-circuit capability, number of switching operations, number of short-circuit interruptions and measurement results.

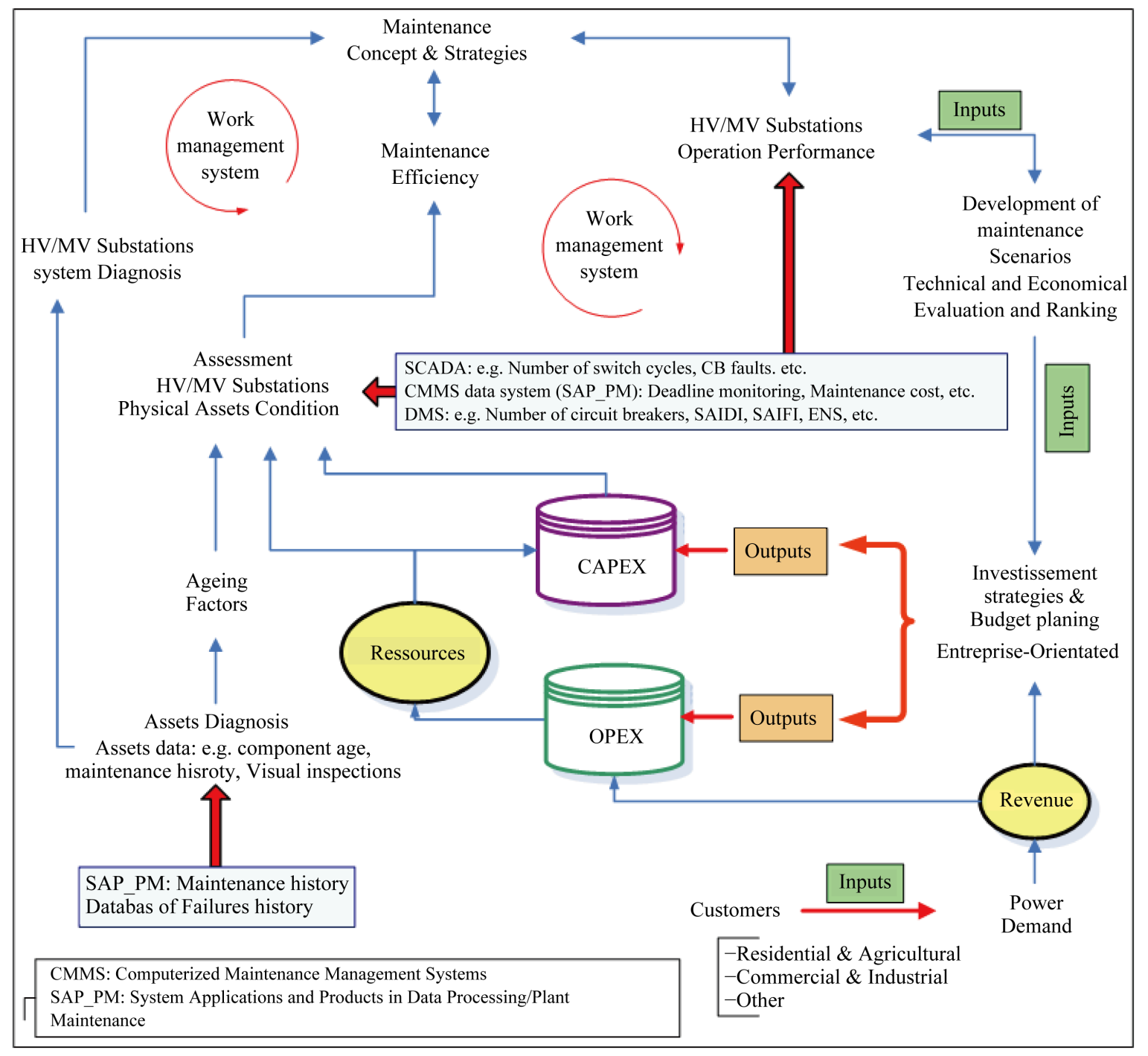

Figure 3. HV/MV DSS maintenance related activities in an AM process. 
Nowadays, investments (Capital expenditure “CAPEX”) or operational expenditure "OPEX” improve the substation condition [23].

The implementation of an AM process within a distribution utility can be described as a human activity system, a system of actor trying to change the way maintenance is performed. The planning preparation and implementation of an AM process therefore resembles a logic transformation process (See Figure 3). Input (the original maintenance performance and customers demand) is converted into Output and then passed to CAPEX \& OPEX (The present study does not address CAPEX options in detail).

Finally, the optimized use of financial resources plays a central role in all areas and hence also in electric power companies. Consequential the utilities are anxious to keep the level of the yearly OPEX as low as possible. CAPEX include the yearly expenditures of new installations due to replacement and grid enlargement. OPEX comprise: maintenance costs due to inspection and overhaul; repair costs due to minor and major failures, outage costs due to expected energy not supplied as well as and power losses. From engineering stand point, the activities in Figure 3 have other meanings. On the one hand, the processes from top to bottom are maintenance optimization related activities. The purpose from top to bottom is to optimize the limited maintenance and budget resources, to ensure reliable power supply and decrease interruption frequency/durations. The activities from bottom to top are evaluation processes. Detailed modeling of aging/maintenance/failure histories will more accurately represent asset values/conditions, in order to better support maintenance resources optimization described before.

\subsection{General Points on HV/MV DSS Equipment Maintenance at ONEEED}

Today, the steady increase of the demand for electric power determines the requirement for high level of reliability and quality of power supply systems. ONEEED HV/MV DSS are composed of various types of equipment, and since most of this equipment has been installed more than several twenty of years ago, its performance inevitably deteriorates. However, the purpose of maintenance is to enable desired component performance by maintaining or returning the HV/MV DSS component's ability to function correctly. Substation maintenance is a process of periodic, planned inspection of and, if necessary, repair, and replacement of all switchgear, buildings, and ancillary equipment in substation installations. In simple terms, substation maintenance is a regimen of regular preventative checks and actions carried out to ensure substations are kept in good working order. This process typically consists of a series of stringent visual and physical inspections and actions carried out according to a set schedule. Equipment replacement may be standard procedure or only upon detection of wear, damage, or substandard operation. All inspection and actions during substation maintenance should be accurately documented and stored for further reference. HV/MV DSS are the most critical part of any electrical supply grid. A failure of a single piece of substation equipment can cause a total grid collapse which may take days or even longer to rectify. For this reason, substation care is one of the most important parts of any electrical department's preventative maintenance schedule. These schedules generally consist of a tiered plan of minor and major maintenance events. Minor maintenance will seldom require any sort of power shut down although major events typically requiring short intervals of supply interruption. Furthermore, the maintenance concept does not provide only one correct operational solution. In this paper, it is divided into preventive and corrective maintenance. Moreover, HV/MV DSS equipment maintenance at ONEEED is performed by local staff (for standard maintenance, among others). Maintenance procedures follow a maintenance policy to be suited to the needs. The maintenance includes systematic preventive maintenance, corrective maintenance (before failure), curative maintenance (after a failure), as well as extensive renovation operations (refurbishment, etc.). Therefore, PM changed from being systematic (with one single maintenance program) to being more targeted (with tasks and frequencies depending on the needs). Those needs depend on the significance and the features of the equipments. The full maintenance process includes inspection, record and action. This is according to procedures. This part explains ONEEED's three categories of maintenance, namely, short, medium and long term maintenance. A short term maintenance program is mainly carried out visually. This is performed on a weekly to monthly basis, medium term maintenance program is carried out at a frequency of less than 2 years, while a long term is carried out at a frequency of 5 years or more and it is the most extensive test of the three. Both medium and long maintenance programs are carried out with the transformers energized [16]. In the following, we present preparing a Preventive Maintenance Plan (PMP) of a HV/MV DSS. The steps and format of preparing a maintenance plan will vary depending on the application and design of maintenance systems. The key steps in preparing a typical 
maintenance plan will include the following:

1) Prepare an asset inventory and identify maintenance activity and tasks.

2) Identify the frequency of the task and develop an annual work schedule, prepare and issue a work order.

Affording such a situation, imposes strengthening the use of condition based tasks related to the state of the art of maintenance techniques, defining so the most appropriate diagnosis evaluations to keep an adequate and up-dated control of condition and to periodically evaluate the obtained results in order to assure their good performance. To reach the proposed goal, ONEEED bases the maintenance strategies applied in HV/MV DSS on a number of key drivers. They include the intensive use of periodic checklist inspections complemented with the development of suitable diagnosis determinations, the systematic monitoring of results and the performing, when necessary, of additional or major maintenance tasks.

The maintenance categories include the following:

a) Routine inspection (RI) and visual and thermographic monitoring: This involves a visual inspection/investigation of the principle features of the substation facilities without requiring them to be taken out of service. Observations resulting from inspections may lead to the decision to carry out further maintenance activities.

b) Inspections shall be carried out on all (CB) and isolators to check for abnormal conditions on the equipment. The conditions and meter readings of the equipment shall be recorded on the approved check sheets or feedback templates provided with job plans [12].

c) Minor maintenance: This involves the execution of scheduled or preventive maintenance work and may require the substation facilities to be taken out of service. Minor maintenance maybe time based and/or operational based. Minor maintenance may also include the assessment of the condition of the substation facilities in ONEEED HV/MV DSS [8].

d) Major maintenance: This involves work performed with the objective of repairing, replacing or modifying parts/facilities as required. Major maintenance may involve the execution of specialized maintenance where specialized knowledge is required (live substation work).

\section{Approach for Optimizing HV/MV DSS Maintenance}

\subsection{Prerequisites for Maintenance Optimization of HV/MV DSS}

In order to perform maintenance optimization there are a number of prerequisites.

1) Most important is a clear objective. Without a clear objective no optimization can be performed. This might seem as a trivial point but it is not completely so. For example, if the objective of the optimization is chosen to be lowest total cost. Then the question of what costs that should be included arise (e.g. shall costs for public relations are included). Related to this discussion is the risk level. That is, the modeler must know how risk in different scenarios shall be valued in the optimization.

2) Data is required, for example failure and repair rates as well as all costs involved and how all components and parts are interconnected and their relationships.

3) A model of the network is required in order to establish the effects of potential maintenance actions on the network. For this adequate reliability modeling, techniques are needed.

4) Lastly, an optimization approach/technique is needed in order to reach the objective. Such a technique requires a relationship between optimization objective and means of control.

\subsection{Benefits and Shortcoming of the Approach}

Maximum asset performance is one of the major goals for electric power system managers. To reach this goal minimal life cycle cost and maintenance optimization become crucial while meeting demands from customers and regulators. One of the fundamental objectives is therefore to relate maintenance and reliability in an efficiently and effectively way, which is the aim of several maintenance methods such as the RCM method. Furthermore, this necessitates the determination of the optimal balance between preventive and corrective maintenance to obtain the lowest total cost. The objective of the maintenance strategy is to ensure that the health of substation facilities in OEXMS substations is managed over their lifecycle. This will ensure optimal reliability, availability and life of the equipment. The maintenance requirements for facilities in OEXMS substations are derived based on the RCM principles. FMECA studies have been carried out for substation facilities in. The results of the FMECA study have been used as the basis of the maintenance execution strategy template. The 
information and data collected during these maintenance activities shall be captured and processed in the relevant maintenance management system. The probability of failure for substation facilities shall be determined assuming best practices are applied over the entire life cycle of the electrical component in OEXMS substations. Finally, the method that we will present in this article can be defined as a global approach searching, the best decisions concerning the operational management of the maintenance works and activities of HV/MV DSS. Indeed, the mission is the planning of the execution of the works stopped on the basis of the evaluation of the HV/MV DSS assets and this one planned during the past year and not yet realized by the operational teams raising the OEXMS. In general, the main objectives looked for with this new methodology is optimize and organize the maintenance activities and work process, improve the productivity and the reactivity of the teams and to develop a defensible logic for valuing and prioritizing preventive maintenance. Moreover in general the aims are summarized as follows:

1) Organization of the maintenance works and improvement of the productivity and the reactivity of the teams through the organization of the maintenance process.

2) To reduce time without tasks to achieve by a better preparation and programming of work by the prioritization of urgent work with a preliminary estimate of the durations of interventions and the time of the way between two different action points.

3) To reduce the necessary work time for the achievement of work by adopting better practices and to minimize the necessary time to the interventions and to group the various necessary interventions on an equipment so as to limit the duration of its consignments while optimizing the time of the way.etc.

\subsection{Overview and Steps of the Developed Approach}

The method that we suggest is based on a logical and simple reasoning that one can be applied inside the HV/ MV DSS. Its aim is to consider the maintenance process within a comprehensive approach. Indeed, The HV/MV substation equipment maintenance policy was redefined using the RCM method with the aim of updating and optimising the maintenance plans as a function of new company objectives. The use and customization of the RCM method for electrical equipment is described, based on experiment feedback, failure analysis, and the search for the best maintenance task and its associated frequency [12]. The proposed target process suggested is centred on the exhaustive identification of the requirements in maintenance by proceeding to a visit of the substation assets, before launching the preparation of the APMPP (Annual preventive maintenance plan project). The method suggested aims at focusing on the efforts on the elements which cause the majority of exploitation and quality of supply harmful effects. Hereinafter we pass to identify the various stages constituting the approach namely:

1) Maintenance assessment: Diagnose, analysis and evaluate the current situation of maintenance activities: The first step of the method consists in identifying, evaluating and mapping of the existing maintenance practice and review existing asset maintenance processes and work practices. One first step is therefore to examine what activities are being performed today, and to take on a discussion on why different solutions have been chosen earlier. Review the last four years history of maintenance work (maintenance costs and man-hours per category to determine proportions of cost and effort spent for each maintenance action) [24] [25]. To this end, we have adopted the methodology developed by two French organizations ADEPA and CETIM [5]. It helps guide companies wishing to evolve and automate their maintenance function. This approach is considered as a sequence of actions to achieve, from the existing state, a certain level of mastery in the various activities of the department in order to pass the state where it suffers the failure to a state where the failure are managed. The aim is to review the current status of the maintenance function of HV/MV DSS and determine its weaknesses and its strengths.

2) Diagnose and implement a detailed and thorough analysis of the actual condition of the HV/MV DSS: overall physical inspection during a predefined time of the N-1 financial year over a period of two months, it covers both the criticality and the importance of assets (PC (Power Circuit) and CPC (Control \& Protection Circuit) as well as its state. From the view of the operator, each equipment or part of distribution network can have more importance than other equipment or parts. Importance is a quality issue and depending on the perspective of each operator, each area or any perception can change. Moreover, the data and information monitoring operational behavior (on the history of faults, the results of measurements, parameters and applied maintenance) are used to quantify the technical condition of the substation components. Indeed, monitoring the operational behavior is performed systematically and involves the acquisition, registration, validation, storage, processing and 
transmission of information and operation of the components and maintenance. The balance of the operational behavior and maintenance is used to examine the evolution and trends in performance for structures, facilities, systems and components, and finally to examine the effectiveness of maintenance [26].

3) Determine of the annual workload for the considered HV/MV DSS: Determine the volume of the projected maintenance work both on the CP and CPC, then estimate the TMWH (Total Maintenance workers Hours) by the operational Teams (SMT (substation maintenance team) and CPCT (control and protection circuit team) and type of maintenance required. Finally, enhance the APMPP in TMWH [4].

4) Determine available and target Maintenance Workforce in TMWH by operational team: The optimum numbers of electricians of different skill levels and from different work sources needed for performing the forecasted maintenance workload (hours/year). The optimal allocation of the maintenance workforce to meet random and varying workload is a complex and challenging problem. It is a problem of determining the needed number of workers with different skill levels and from different sources to meet maintenance workload of different grades. In particular, it is the determination of the number of direct hired, overtime, with different skill levels needed for a specified planning horizon in which maintenance workload of different grades is required to be performed with minimum cost acquired. The determination of maintenance workforce involves the consideration of several important factors. Specifically, it involves the consideration of the following:

a) Planning horizon and maintenance workload for each maintenance work grade in each time period of the planning horizon.

b) Healthy backlog for maintenance works of each maintenance work grade in each time period of the planning horizon and productivity of maintenance workers.

5) Show the difference between the necessary TMWH for the realisation of all the work and the one available on the basis of: a timing and standard normative durations which were attributed to each operation within the framework of a range of maintenance it on the basis of the history of the realized works and the experiment feedback, of the frequency of each operation and the travel time.

6) Rethink, where necessary, the sizing of the teams of maintenance supported by benchmarks. Size and modernize the operational logistics of the teams. Indeed, proper ways of executing maintenance programs depend on good scheduling of the maintenance workload which in turns depends on good planning of maintenance resources good planning means proper determination of the maintenance resources that are needed to meet the maintenance workload to be performed during the planning horizon. In particular, good planning deals with good determination of:

a) Skills of maintenance workers, and exact number of maintenance workers of various crafts and types of maintenance equipment and tools.

b) Exact number of maintenance equipment and tools.

c) Specifications of spare parts and materials.

d) Exact number of spare parts and materials.

e) Right level of work backlog and overtime capacity: The most complex element among all of these essential elements of planning is the determination of the exact number of maintenance workers of various crafts.

7) Prioritize maintenance tasks: The management of resources can be an obstacle to the implementation of a defined maintenance program. The managers have a limited number of resources to carry out both tasks in the context of MP and MC policy. Due to budgetary constraints, or other circumstances creating an unavailability of maintenance resources [4], they can be brought to review the program established and suspend or cancel the performance of certain tasks. Indeed, it is necessary to be able to identify carefully the tasks could be delayed without causing unacceptable consequences for the performance of the installation. It is then necessary to be able to prioritize tasks according to their value and the risks they can avoid.

8) Optimize the PM program (deadlines and resources) for HV/MV DSS and develop RCM processes: In order to increase the operational reliability of the system and decrease both down time and maintenance cost, a RCM strategy has been used [3] [27]. Once the critical failure modes have been identified, a maintenance strategy can be selected based on logical RCM decision for maintenance optimization. RCM optimizes the various maintenance strategies based on the findings from the functional failure analysis. For HV/MV DSS, planning and implementing an APMPP under the RCM approach can be complicated due to the variety of assets installed in SS under different operating conditions. A key focus area when implementing RCM is that inspection manuals and procedures should be designed and prepared by a technical team with both field and exploitation experience. This on the one hand, will help the maintenance engineers to ensure that the service technicians' tasks 
are aligned to design guidelines so that after a series of maintenance tasks or inspections, the results will be easily correlated to the maintenance information. While on the other hand, those with field experience will ensure that the technical guidelines can be interpreted into a language the service technicians understand.

9) Define the maintenance task lists for the maintenance of HV/MV DSS by item and structure: PC and CPC: Maintenance task lists describe a sequence of individual maintenance activities which must be performed repeatedly within a company. Task lists are used to standardize these recurring work sequences and to plan them more effectively. Task lists help to reduce the maintenance effort when standardized work sequences change, for example as a result of new legal regulations. We must carry out the changes at exactly one place in the corresponding maintenance task list. All maintenance orders and maintenance items that refer to the maintenance task list automatically receive the actual status of the work sequences.

10) Finalize the optimized preventive maintenance plan and introduced the operating ranges for HV/MV DSS PM program in a CMMS/SAP PM, to automate creation, the edition and the monitoring of the work orders (WO). Also the work resulting from the annual inspection of HV/MV DSS and those with punctual character will be incorporated in the planned orders before validation maintenance.

11) Formalize the monitoring of execution of the maintenance program. The system of checking the maintenance results consists in monitoring the operational behaviour of facilities, before and after carrying out the maintenance work, respectively. The history of the maintenance work and of the operation behaviour points out the equipment operational trends, the weak points, improvement needs. The results from maintenance activities can in general be difficult to measure in an objective manner. This is due to the fact that maintenance primarily has the purpose of preventing unwanted events.

12) Raise the level of skills by organizing exchange visits with other national and international managers to inquire about technological advances and methods (benchmarking and technology watch).

\section{Case Study: Implementing Approach}

In the following case study, we present the results obtained after the implementation of this approach in the OEXMS that manages a portfolio of $13 \mathrm{HV} / \mathrm{MV}$ DSS at a large metropolitan area in eastern of Morocco.

\subsection{Classification of the HV/MV DSS Assets by Their Criticality}

After determining of HV/MV DSS critical equipment until 5 years (See Table 1 that summarizes some results), we have given the priority to the (PTR), (EL), (IS) and (CB) for starting our approach, then the result of optimizing maintenance works is summarized in the summary table (See Table 1 and Table 2). The following tables highlight examples of routine and preventive maintenance tasks after the RCM studies.

\subsection{The Target Potential and the Completion Percentage of the APMPP}

The identification of the target capacity of the all teams is based on a separation between the requirements to preventive work and those for routine visits. The synthesis of the scheduled PMP to perform for the year 2012

Table 1. Examples of routine and preventive maintenance tasks after the RCM studies.

\begin{tabular}{|c|c|c|}
\hline Asset & Critically & Maintenance action \\
\hline ARS & 4 & -Preventive systematic maintenance (PSM) action and RI. \\
\hline $\mathrm{BB}$ & 18 & -PMS action and RI (eq. Infrared inspection). \\
\hline SW & 24 & -PMS action and RI. \\
\hline FUS & 48 & -PMS action and RI. \\
\hline IS & 72 & $\begin{array}{l}\text {-Corrective action: They can be covered with grease or washed regularly. } \\
\text {-PMS action and RI. }\end{array}$ \\
\hline $\mathrm{CB}$ & 100 & -Special surveillance, conditional /PM (SCADA monitoring). \\
\hline DL & 147 & $\begin{array}{l}\text {-Corrective action: If the fault is minor. } \\
\text {-PSM action (SCADA monitoring). }\end{array}$ \\
\hline PTR & 175 & $\begin{array}{l}\text {-Special surveillance, conditional /PM (SCADA monitoring). } \\
\text {-PMS action and RI. }\end{array}$ \\
\hline
\end{tabular}


Table 2. The target potential to realize the APMPP.

\begin{tabular}{lccc}
\hline Team & $\begin{array}{c}\text { Available potential of the teams } \\
\text { in year 2012 in TMHW }\end{array}$ & $\begin{array}{c}\text { Potential wanted } \\
\text { in TMHW }\end{array}$ & $\begin{array}{c}\text { The difference in } \\
\text { TMHW }\end{array}$ \\
\hline SMT and et CPCT & 13944 & 18564 & -4620 \\
Potential lost due to the teams interventions (Fortuitous incidents) & & 1345 \\
New Potential of the teams in year 2012 in TMHW & 12599 \\
The cover of APMPP 2012 in $\%$ & $68 \%$ \\
\hline
\end{tabular}

has allowed us to initially identify the target potential in TMHW for all of 13 HV/MV DSS. The necessary target potential for the implementation of the APMPP is around 18564 TMHW (See Table 2), it is summation between the potential to carry out the work plan based on the 2011 action plan [12] and the potential necessary to achieve the various visits for all HV/MV DSS, the following Table 1 summarizes the results that were obtained.

\subsection{Optimization of the PMP Using a CMMS/SAP PM}

With the advent of new technologies, the CMMS is introduced to enhance maintenance of HV/MV DSS. A CMMS is a type of management software that performs functions in support of management and tracking of O\&M activities. It involves some software in tracking the SS installed in OEXMS. The SAP PM module is a CMMS used in ONEEED, and this module is part of larger SAP Enterprise Resource Planning (ERP) system used within ONEED. The use of SAP PM in distribution is presently limited to commercial activities [6] [20], the resource cost recovery part of the system is presently not used optimally. The use of the CMMS which is a computerized maintenance work execution system helping companies/enterprises to manage work orders, material and purchasing, has made the maintenance management easier to improve the operations. The newer versions of CMMS also calculate the costs and repair history. The process, as a work order module, receives maintenance input, creates work orders and tracks work in progress (process). It also generates reports, like work status and equipment availability. A SAP PM system automates most of the logistical functions performed by maintenance staff and management. Some of its many functions and benefits include the following:

4) Production of work orders, prioritization, and tracking of equipments/systems and historical tracking of all work orders generated which become sortable by equipment, date, person responding, etc.

5) The tracking of scheduled and unscheduled maintenance activities [28].

6) Earlier detection of impending problems before a failure and allow a higher level of planned maintenance activities that lead to a more efficient use of staff resources.

7) Affects inventory control, enabling a better spare parts forecasting to minimize existing inventory and reduce shortage.

The steps and format of preparing a maintenance plan will vary depending on the application and design of maintenance systems [29]. The key steps in preparing a typical maintenance plan will include the following:

8) Prepare an HV/MV DSS inventory and identify maintenance activity and tasks.

9) Identify the frequency of the task and develop an annual work schedule.

10) Prepare and issue a work order.

The purpose of maintenance planning with SAP PM is for ensuring a high availability of objects in the long term is an important part of Plant Maintenance. Planned maintenance is used to avoid system breakdowns or the breakdown of other objects, which-in addition to the repair costs often result in much higher costs subsequently owing to supply breakdown. There are many benefits in using planned maintenance.

It is the generic term for inspections, PM and planned repairs, for which the time and scope of the work can be planned in advance.

In addition to internal ONEEED aspects for planned maintenance, external factors should also be considered. An increasing number of conditions set by legislative bodies demand more stringent requirements on planned monitoring and maintenance of objects. External requirements can be:

a) Manufacturer recommendations: The manufacturer of your technical objects may recommend certain procedures to ensure that the objects always function optimally.

b) Legal requirements: There may be labor protection laws or laws concerning the safety of objects, which require you to maintain your technical system on a regular basis. 
c) Environmental requirements: Effective planned maintenance can also help to prevent breakdowns, which could lead to environmental hazards.

The diagram "Figure 4" presents all the steps in the SAP PM process to follow for creating MTL following the RCM analysis. Also; Figure 5 shows an example of a MTL for HV/MV DSS covered by OEXMS. All routine inspection/preventative maintenance work will need to be managed from within the SAP environment, by the generation of Plant Maintenance work orders for HV/MV DSS assets. Scheduling of the work orders will be undertaken, such that all assets within the nominated periods outlined in RCM maintenance strategy [30] [31]. The date inspected, along with all identified defects/non routine maintenance found during the inspection/ preventative maintenance work, including those that have been rectified will be recorded through SAP PM. This information will provide the basis for any future evaluation of the effectiveness of this policy.

\subsection{Results and Discussion}

The Table 2 shows the obtained difference between the existing and the target potential to realize the totality of APMPP 2012 is of the order 4620 TMWH (See Table 2). Indeed, the analysis of this table shows clearly that the manager may only make $68 \%$ of the APPMP (See Table 2) before the implementing the maintenance approach of the HV/MV DSS.

The results in Table 3 shows that the necessary target potential in TMHW for the realization of the whole maintenance plan after the implementing the new optimization approach is of 18564 TMHW (See Table 3).

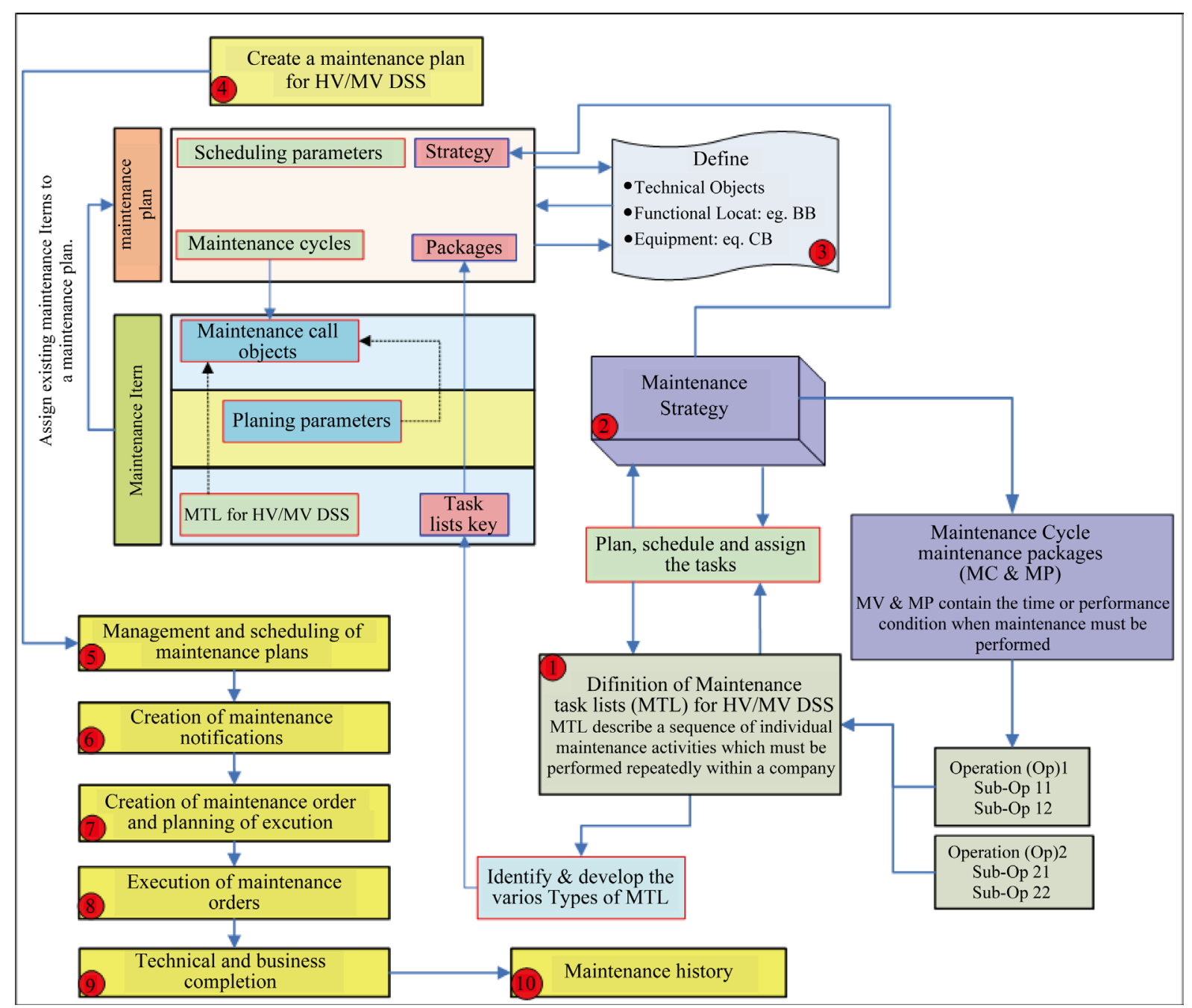

Figure 4. HV/MV DSS maintenance processes with SAP PM. 


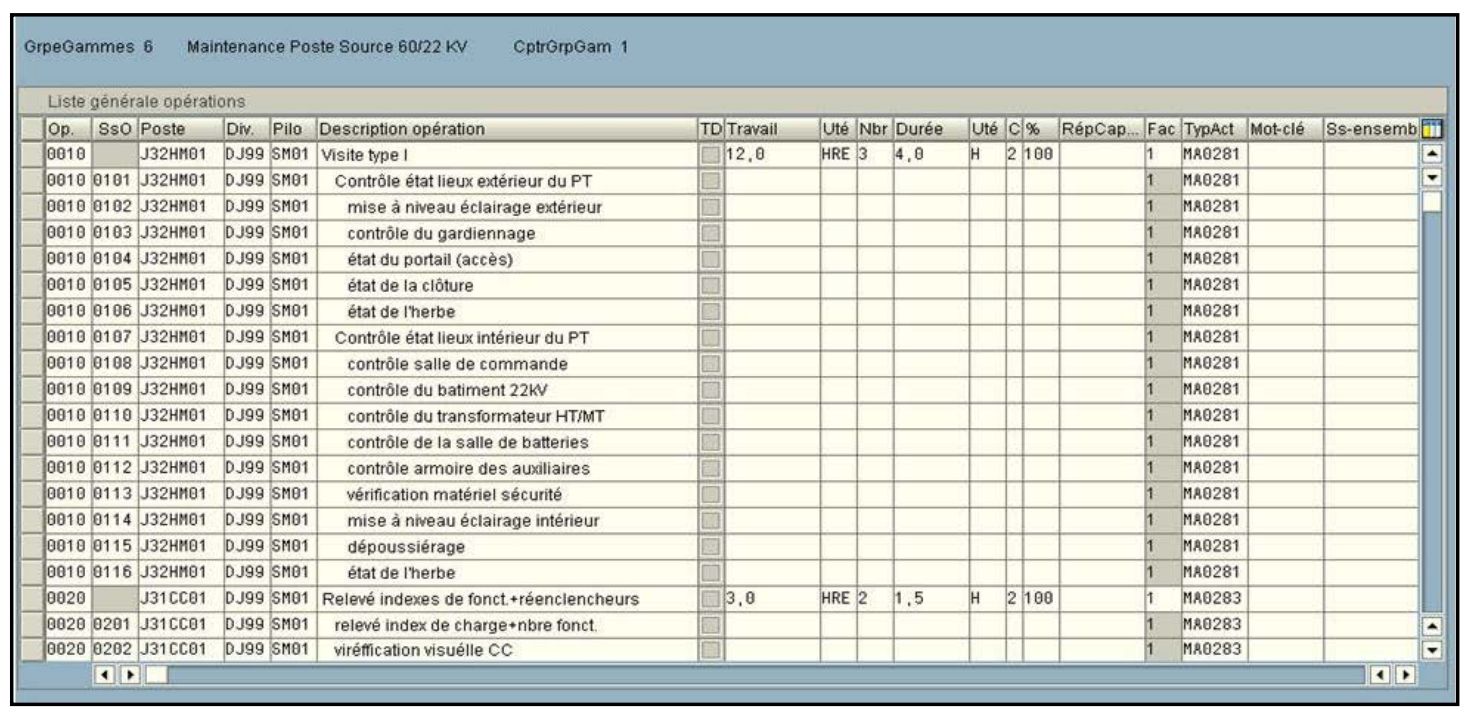

Figure 5. Example of a HV/MV DSS maintenance task lists.

Table 3. Gain by adopting the approach gain.

\begin{tabular}{|c|c|c|c|c|}
\hline Team & $\begin{array}{l}\text { Available potential of the } \\
\text { teams in year } 2012 \text { in } \\
\text { TMHW }\end{array}$ & $\begin{array}{l}\text { Target potential in } \\
\text { TMHW }\end{array}$ & $\begin{array}{l}\text { Gain by adopting } \\
\text { SAP PM and RCM } \\
\text { approach TMHW }\end{array}$ & $\begin{array}{c}\text { The gain recovered through the use } \\
\text { of new appropriate materials in } \\
\text { TMWH }\end{array}$ \\
\hline SMT and CPCT & 13944 & 18564 & 1985 & 1406 \\
\hline \multicolumn{2}{|c|}{$\begin{array}{l}\text { The cover of APMPP } 2012 \text { in \% after } \\
\text { implementing the approach }\end{array}$} & \multicolumn{3}{|c|}{$93 \%$} \\
\hline
\end{tabular}

Indeed, as it is shown in Table 3, we could improve the team's productivity by gaining 3391 TMHW at the end of 2012. This time was calculated on the basis of timing on the ground of various maintenance actions (and by frequency of maintenance scheduled given to each group according to the assets criticality, obtained with RCM methodology, enabled us to obtain the new TMWH after optimization.) by using these new materials by the exploiting. The optimization approach was applied to the HV/MV DSS maintenance activities since the 2012 financial year. The achieved results are:

1) The percentage of realization of the APMPP obtained after implementing of the developed approach is about 93\%. Thus from performance point of view and with the existing potential, the adoption of this method has improved the capability of execution of APPMP of $27 \%$ at the level of OEXMS.

2) According to the ONEEED interruption statistics from year 2012, the new proposed approach for HV/MV DSS maintenance activities has allowed the reduction of the full number of the incident and interruptions registered on the SCADA by 15\% (55 outages at the end of the year 2011 against 44 at the end of the year 2012).

3) A reduction of the cumulative interruption duration at the end of the 2012 financial year comparing with the 2011 results.

4) A reduction of $25 \%$ of the TMHW worked in the HV/MV DSS maintenance activities at the end of the financial year 2012, in this same period the OPEX showed an improvement of 18\% comparing the 2011 and 2010 amounts.

5) An improvement of the indicators of performance SAIFI and SAIDI respectively by $12 \%$ and $16 \%$. On the other hand, the achieved result was a reduction of 15\% in ENS comparing with the 2010 and 2009 results.

\section{Conclusions}

Today, the key issue for operation and control of HV/MV DSS is to find the optimal balance between cost efficiency and power quality. This research was set out to improve the existing maintenance strategy associated with RCM of HV/MV DSS with different structures. The developed method has been shown to be an effective 
tool for the optimization of routine maintenance in the area of HV/MV DSS. In this context, a reasonable preventive maintenance planning based on AM method becomes indispensable. To find its best possible way, detail and quantified information on both costs and supply reliability is required including prediction of the present and future performance of all equipment. Indeed, reducing O\&M costs and preserving service reliability are the top priorities for managers of utility distribution systems. The approach outlined in this paper supports the assessment of a new optimization maintenance strategy as applied to HV/MV DSS. Outcomes are measured in terms of OPEX, ENS, cost of unserved energy and reliability measurement indices such as SAIDI and SAIFI. However, the present electric distribution markets impose reducing programmed maintenance outages in number and duration. Being for distribution utilities a strategic physical asset, special attention must be put on the maintenance of power HV/MV DSS, to improve their availability and reliability. To afford this situation, a new strategic approach model to optimize the maintenance of HV/MV DSS has been developed. The aim of the developed methodology is focused on improving the maintenance management of power HV/MV DSS concerning the use of human, technical and economical resourced, increasing at the same time, the reliability and availability of such physical assets. However, the result obtained from this research has shown that maintenance has a way of improving the KPI's of the amount invested in installing and building of a HV/MV DSS.

Finally, the concept introduced in this paper is a response to any business distribution of electrical energy that wants to rethink its maintenance system in the new economic environment increasingly demanding. We have proposed a flexible and easy method to implement, an integrated methodology that combines strategic, technical and economic criteria taken into account in other tools to aid decision. The targets aimed at within a systemic approach are as follows:

a) Maximizing the availability of the HV/MV DSS, and justifying the maintenance and rehabilitation decisions.

b) Determining the strategy, objectives, responsibilities, requirements and the manner to carry them out with respect to performing the maintenance activity.

c) Providing reliability of equipment and increasing the operational safety.

d) The extension of the operational life of HV/MV DSS fixed assets.

\section{Acknowledgements}

The work presented in this paper has been carried out at the ONEEED. During this time we have received generous support from a large number of people, who in different ways have contributed to the completion of this work. Indeed, the authors are indebted to the many colleagues at the ONEEED/OEXMS who have contributed significantly to the development of this approach and putting at our disposal the technical data necessary for the completion of this work. Furthermore, the authors are indebted with the anonymous referees for their valuable comments which have led to a significant improvement of the paper contents.

\section{References}

[1] Zille, V. (2009) Modélisation et évaluation des stratégies de maintenance complexes sur des systèmes multi-composants. Ph.D. Thesis, Troyes University, Troyes.

[2] Chelbi, A. and Ait-Kadi, D. (2002) Classement des equipements par ordre de priorite pour la maintenance: Une approche multicritere. Journal of Decision Systems, 11, 91-108. http://dx.doi.org/10.3166/jds.11.91-108

[3] Eriksson, R. (2005) A Reliability-Centered Asset Maintenance Method for Assessing the Impact of Maintenance in Power Distribution Systems. IEEE Transactions on Power Systems, 20, 75-82. http://dx.doi.org/10.1109/TPWRS.2004.840433

[4] Hilber, P. (2008) Maintenance Optimization for Power Distribution Systems. Ph.D. Thesis, Department of Elect. Power Engineering, KTH, Stockholm.

[5] El Aoufir, H. and Bouami, D. (2007) Proposition d'un schéma d'évolution des structures maintenance. 5th International Conference of CPI'2007, Rabat, 22-24 October 2007, 20p.

[6] Veldman, J., et al. (2011) Methodology and Theory Typology of Condition Based Maintenance. Journal of Quality in Maintenance Engineering, 17, 183-202. http://dx.doi.org/10.1108/13552511111134600

[7] International Council on Large Electric Systems (Cigre) (2011) Guide for Transformer Maintenance.

[8] Natti, S., et al. (2004) Circuit Breaker and Transformer Inspection and Maintenance: Probabilistic Models. 8th Interna- 
tional Conference on Probabilistic Methods Applied to Power Systems, Iowa State University, Ames, 12-16 September 2004, 1003-1008.

[9] Suttell, R. (2006) Preventive HVAC Maintenance Is a Good Investment. The Source for Facility Decision Makers Buildings. www.buildings.com

[10] Electric Power Research Institute (EPRI) (2001) A Review of the Reliability of Electric Distribution System Components. Technical Report. http://www.epri.com

[11] Hilber, P. and Bertling, L. (2004) Monetary Importance of Component Reliability in Electrical Networks for Maintenance Optimization. Proceeding of the 8th International Conference on Probabilistic methods Applied to Power Systems, Ames, 12-16 September 2004, 150-155.

[12] Data Technique of OEXMS/ONEED, 2012.

[13] Wolff, P. (1996) Maintenance predictive: Une approche stochastique. Ph.D. Thesis, Metz University, Metz.

[14] El-Akruti, K. and Dwight, R. (2013) A Framework for the Engineering Asset Management System. Journal of Quality in Maintenance Engineering, 19, 398-412. http://dx.doi.org/10.1108/JQME-01-2012-0002

[15] Rausand, M. (1998) Reliability Centered Maintenance. Reliability Engineering and System Safety, 60, 121-132. http://dx.doi.org/10.1016/S0951-8320(98)83005-6

[16] Herrou, B. and El Ghorba, M. (2005) Démarche d'optimisation du plan d'action maintenance, étude de cas d'une PME marocaine. 4th International Conference of CPI'2005, Casablanca, 9-11 November 2005, 1-9.

[17] Herrou, B. (2005) The FMECA a Powerful Tool for Maintenance Optimization, Application to a Compressor of a Morrocan PME. 4th International Conference of CPI'2005, Casablanca, 9-11 November 2005, 12p.

[18] Hamadache, M. (2010) Détermination des besoins pour l'élaboration d'une stratégie de maintenance des équipements automatisés du réseau aérien de distribution d'électricité à moyenne tension. M.S. Thesis, Department of Automated Manufacturing Engineering, ETS, Montréal.

[19] Yssaad, B., et al. (2012) Maintenance Optimization for Equipment of Power Distribution Based on FMECA Method. Acta Electrotehnica, 53, 218-223.

[20] Otsmani, Z., et al. (2011) A Genetic Algorithm to Minimize the Periodic Preventive Maintenance Cost in Electrical System. International Review of Electrical Engineering (I.R.E.E.), 6, 1439-1446.

[21] Garg, A. and Deshmukh, S.G. (2006) Applications and Case Studies Maintenance Management: Literature Review and Directions. Journal of Quality in Maintenance Engineering, 12, 205-238. http://dx.doi.org/10.1108/13552510610685075

[22] Orcesi, A. (2008) Étude de la performance des réseaux d’ouvrages d'art et détermination des stratégies de gestion optimales. Ph.D. Thesis, Paris XII University, Paris.

[23] Schreinerm, Z. (2004) Asset Management Optimization, a New Approach to Protection Maintenance. 8th IEE International Conference on Developments in Power System Protection, Amsterdam, 5-8 April 2004, 289-294. http://dx.doi.org/10.1049/cp:20040120

[24] Manel, B. (2010) Evaluation des performances de la maintenance, une approche par simulation. Proceedings at the International Conference on Industrial Engineering and Manufacturing ICIEM'10, 9-10 May 2010, Batna, 333-340.

[25] Jamali, M., et al. (2000) Outils d'aide à la mise en oeuvre d'un système de gestion de maintenance productique, méthodes et outils. Journal Européen des Systèmes Automatisés, 34, 391-407.

[26] Chaker, A. and Benaicha, H. (2010) Méthode de sureté de fonctionnement pour une maintenance efficace Application à un poste électrique. Quatrième Conférence Internationale sur le Génie Electrique CIGE’10, Université de Bechar, Algérie, 3-4 November 2010, 33-38.

[27] Rausand, M. and Hoyland, A. (2003) System Reliability Theory: Models, Statistical Methods and Applications. 2nd Edition, John Wiley \& Sons, New York. http://dx.doi.org/10.1002/9780470316900

[28] SAP PM Library. http://help.sap.com

[29] Heo, J.H., et al. (2014) Implementation of Reliability-Centered Maintenance for Transmission Components Using Particle Swarm Optimization. Journal of Electrical Power and Energy Systems, 55, 238-245. http://dx.doi.org/10.1016/j.ijepes.2013.09.005

[30] Brown, R.E. (1996) Reliability Assessment and Design Optimization for Electric Power Distribution Systems. Ph.D. Dissertation, University of Washington, Seattle.

[31] Afefy, I. (2010) Reliability-Centered Maintenance Methodology and Application: A Case Study. Engineering, 2, 863-873. http://dx.doi.org/10.4236/eng.2010.211109 